\title{
Management of Severe Class II Division 1 Malocclusion with Hybrid Functional Appliance by Double Advancement - A Case Report
}

\author{
Dr. Mukesh Singla(PG Student $)^{1,}$ Dr. Prabhuraj Kambalyal (HOD) ${ }^{2}$, \\ Dr. Nitin Dungarwal (Reader) ${ }^{3}$. Dr. Piyush Bolya (Reader) ${ }^{4}$ \\ Department Of Orthodontics \& Dentofacial Orthopedics, Darshan Dental College \& Hospital, Udaipur.
}

\begin{abstract}
Class II malocclusion is a challenging anomaly in orthodontic practice. The primary treatment goal in Class II mandibular retrognathism cases is to induce supplementary lengthening of the mandible via functional appliances, In case of any remaining dental discrepancy, a fixed appliance is obligatory. This patient was 10 year old growing female with convex profile, retruded chin, lower lip trap with class II skeletal and dental relationship with high overjet \& overbite. Treatment started with Hybrid Functional Appliance (Twin Block with Lip Bumper and Expansion Screw) and then, secondary advancement done within same Appliance. This was followed by fixed mechanotherapy to align and level the dentition, close the spaces and retract the maxillary anteriors.
\end{abstract}

Keywords: Class II Division1, Hybrid Functional Appliance.

\section{Introduction}

Class II malocclusion is a challenging anomaly in orthodontic practice. The development of this malocclusion is due to mandibular retrognathia, maxillary protrusion, or both. It has been reported that retrusion of the mandible is the factor that most commonly contributes to a Class II malocclusion.Various types of functional appliances (eg, activator, bionator, Frankel, and Herbst) are used for the correction of Class II skeletal and occlusal disharmonies in growing patients. Over recent decades, Twin-block appliances, which were originally developed by Clark $^{2}$ in the late 1970s, have increased in popularity. The primary treatment goal in Class II mandibular retrognathism cases is to induce supplementary lengthening of the mandible via functional appliances. However, rather than skeletal, their effect is mainly dentoalveolar. Hence, in an effort to increase the orthopedic impact, attention has been drawn to the timing of treatment, ${ }^{3}$ type of functional appliance, ${ }^{4,5}$ rigidity of the fixed functional appliance ${ }^{6-9}$, and mode of mandibular advancement during treatment ${ }^{10-12}$ (single or gradual activation). The consensus is that condylar growth can be stimulated efficiently if the functional treatment is performed during the adolescent growth spurt using rigid functional appliances.

The experimental study of Rabiel ${ }^{12}$ demonstrated that bone formation at the condyle and glenoid fossa that reached the highest level during the first 30- day period with maximum "jumping" returned to the amount attained during natural growth from then on, while there was significantly more bone formation with stepwise advancement than with maximum jumping in the second 30-day period. Also, from the clinical standpoint, it has been stated that stepwise advancement could result in an increase of mandibular growth, less protrusion of the mandibular incisors, and better patient compliance.In this case report, we used a removable double advancement Hybrid functional appliance (Twin Block with Lip Bumper and expansion screw) followed by fixed mechanotherapy in severe skeletal class II Div 1 with lip trap in 10 year old growing patient.

\section{Diagnosis}

The patient was a 10 year old growing female with a skeletal class II jaw base relationship. She had orthognathic maxilla and retrognathic mandible with convex profile, posterior facial divergence, an acute nasolabial angle, incompetent lips, and deep mentolabial sulcus with lip trap and retruded chin. Intraorally, mixed dentition was present in all four quadrants. Molars were in class-II relation on both sides. Incisors were in class II relationship with Overjet was $12 \mathrm{~mm} \&$ overbite was $6 \mathrm{~mm}$. (Fig: 1). The lateral cephalometric analysis showed a class II skeletal pattern that resulted from ANB: $6^{0}$, Wit's Appraisal: $3 \mathrm{~mm}$. Both the maxillary and mandibular incisors were labially proclined (U1-SN: 115 ; L1-MP: $97^{0}$ ). Evalution of patient's cervical vertebrae maturity indicators (CVMI) suggested that the patient was in a pubertal growth spurt, which indicated optimal timing for orthopaedic therapy for a Class II disharmony.

No symptoms of temporomandibular joint disorder were detected. 

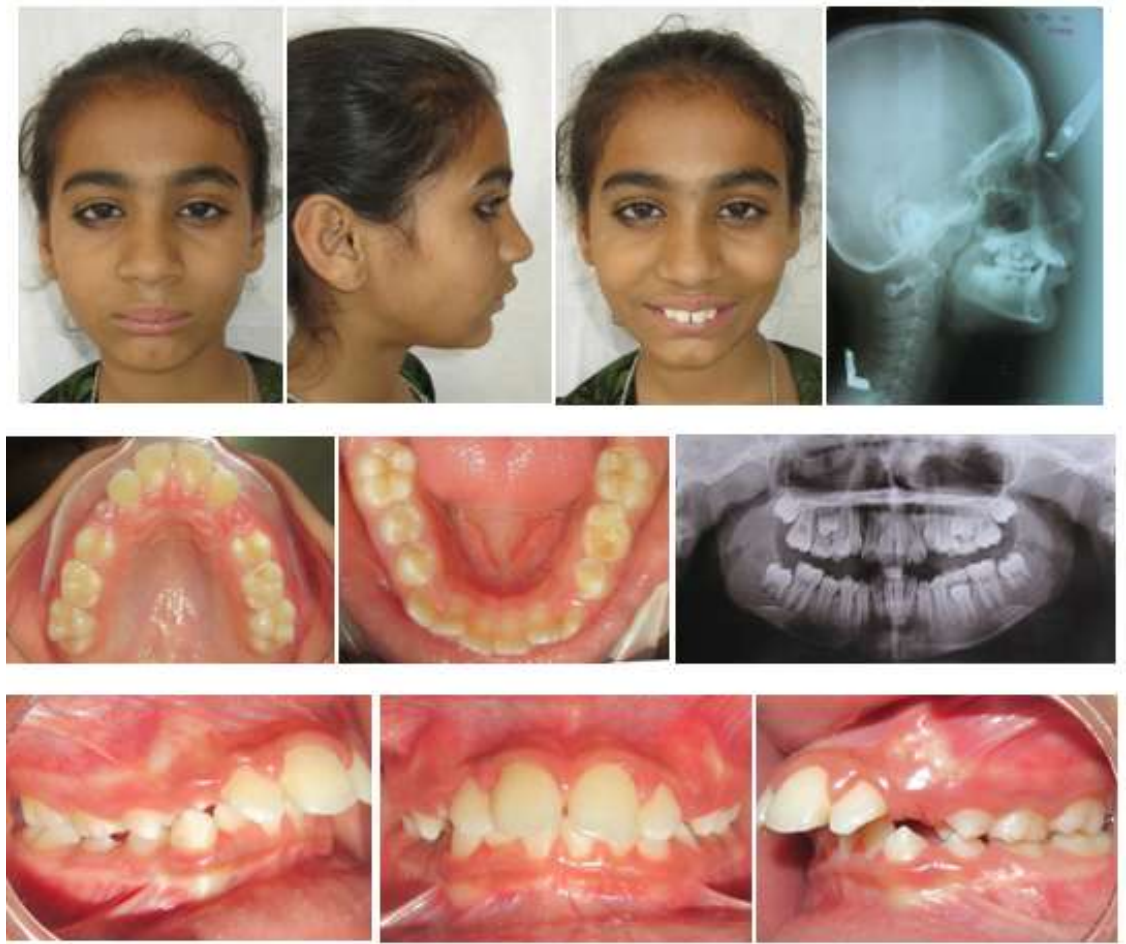

Fig: 1 pre-treatment records (extraoral, intraoral and raidographs)

\section{Treatment Plan:}

The pubertal growth status of a patient is more critical for sagittal correction. So, we decided to institute the first phase of treatment by carrying out the sagittal correction with functional orthopaedic approach. A removable Hybrid Functional Appliance (Twin Block with Lip Bumper and Expansion Screw) was choosen to stimulate the forward mandibular growth. This was to be followed by secondary advancement in same appliance and to be followed by second phase of treatment with fixed-appliance mechanotherapy for space closure, retraction of the anterior teeth and finishing $\&$ detailing of the occlusion.

\section{Treatment Progress:}

The Twin Block appliance was fabricated with $1^{\text {st }}$ advancement (Horizontal: $6 \mathrm{~mm} \&$ Vertical: $4 \mathrm{~mm}$ ) (Fig: 2a). The patient was instructed to wear the appliance full-time except contact sports. After 8 months of good compliance, the patient showed a class I molar relationship and end-on canine relationship with improved profile.
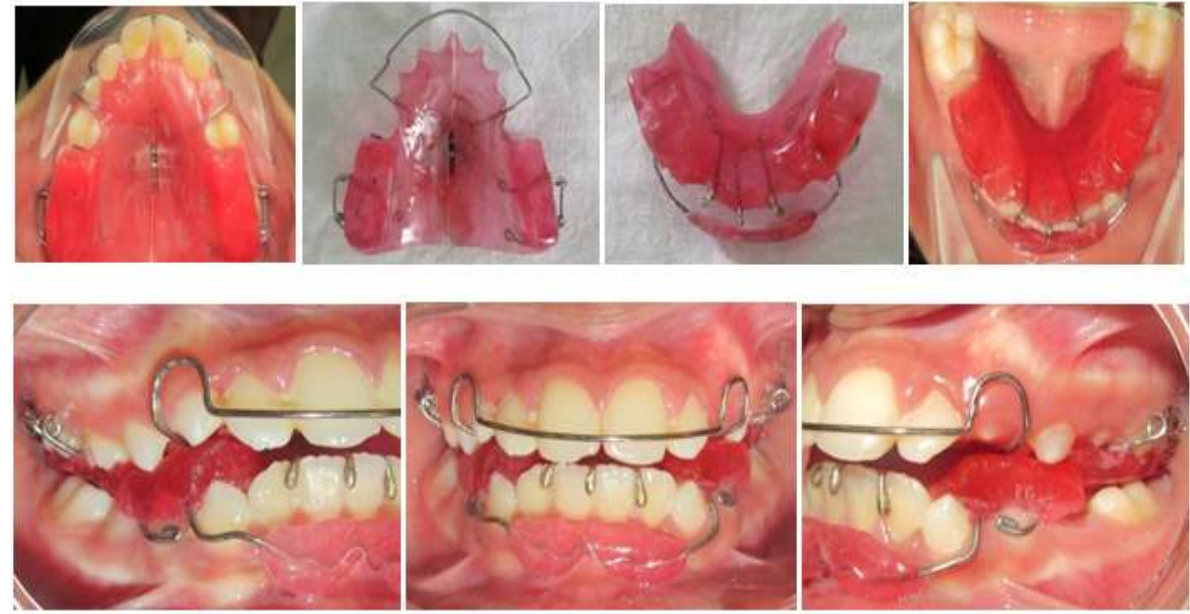

(a) $1^{\text {st }}$ advancement: $\mathrm{H}=6 \mathrm{~mm}, \mathrm{~V}=4 \mathrm{~mm}$ 


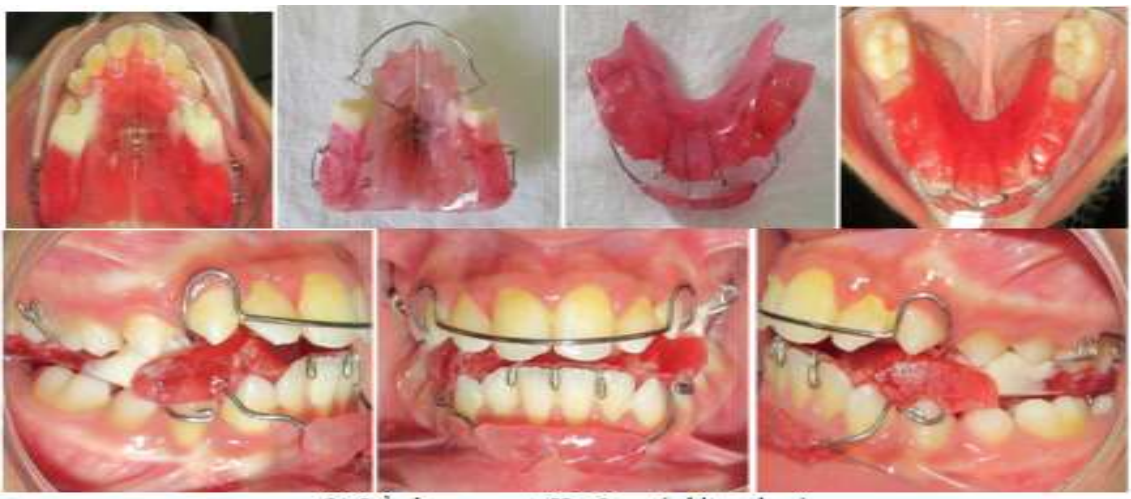

(b) $2^{\text {nd }}$ advancement: $\mathrm{H}=2 \mathrm{~mm}$ (white colour)

Fig: $21^{\text {st }}$ and $2^{\text {sd }}$ advancement of the same Hybrid Functional Appliance

By taking $2^{\text {nd }}$ VTO, patient showed considerably improved facial profile. Then, $2^{\text {nd }}$ advancement (Horizontal: 2mm) was fabricated in same Twin Block appliance (Fig: 2b). At the end of this phase of treatment, the patient presented a super class I molar relationship and class I canine relationship with an overjet \& overbite of 4mm. (Fig: 3) Phase II treatment with a preadjusted edgewise appliance (PEA) was initiated with McLaughlin Bennet Trevisi (MBT) prescription 0.022" brackets and then directly bonded. Leveling and aligning was done using nickel-titanium (NiTi) wires. The patient is currently at the stage of 0.019 " $\mathrm{x} 0.025$ " SS with class II elastics of treatment. The molar and canine relationship is in class I. (Fig: 4)

All that now remains for achieving proper finishing and detailing of the occlusion.
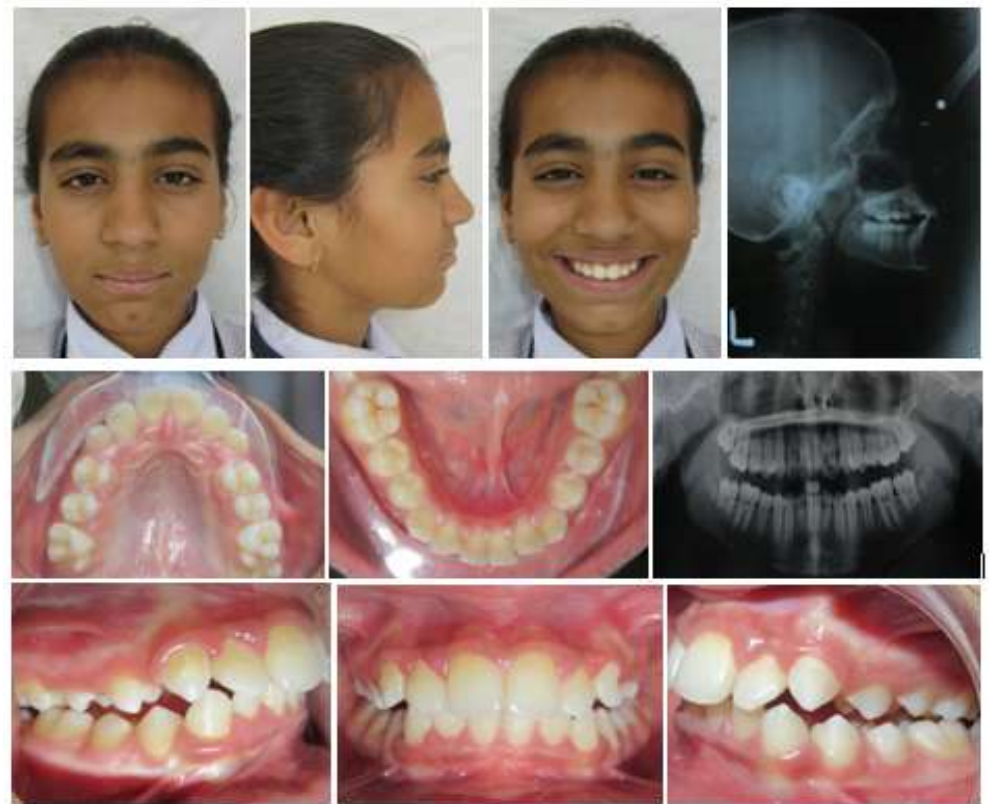

Fig: 3 Post-Functional Records (Extraoral, Intraoral And Raidographs)

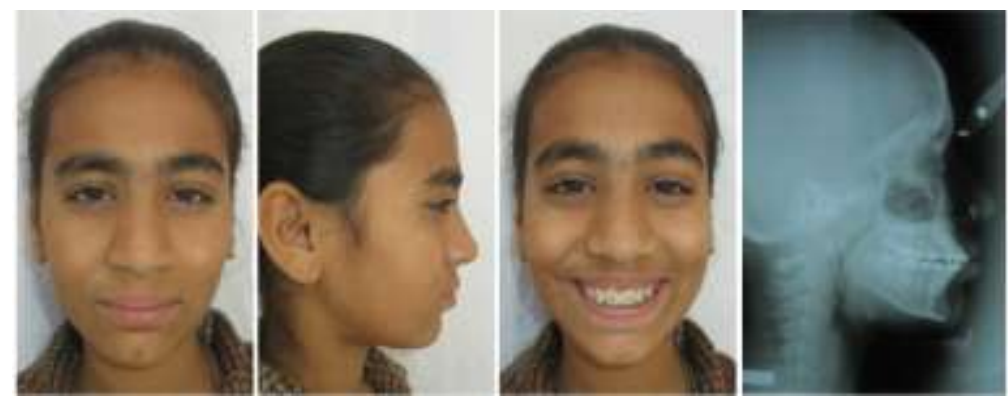



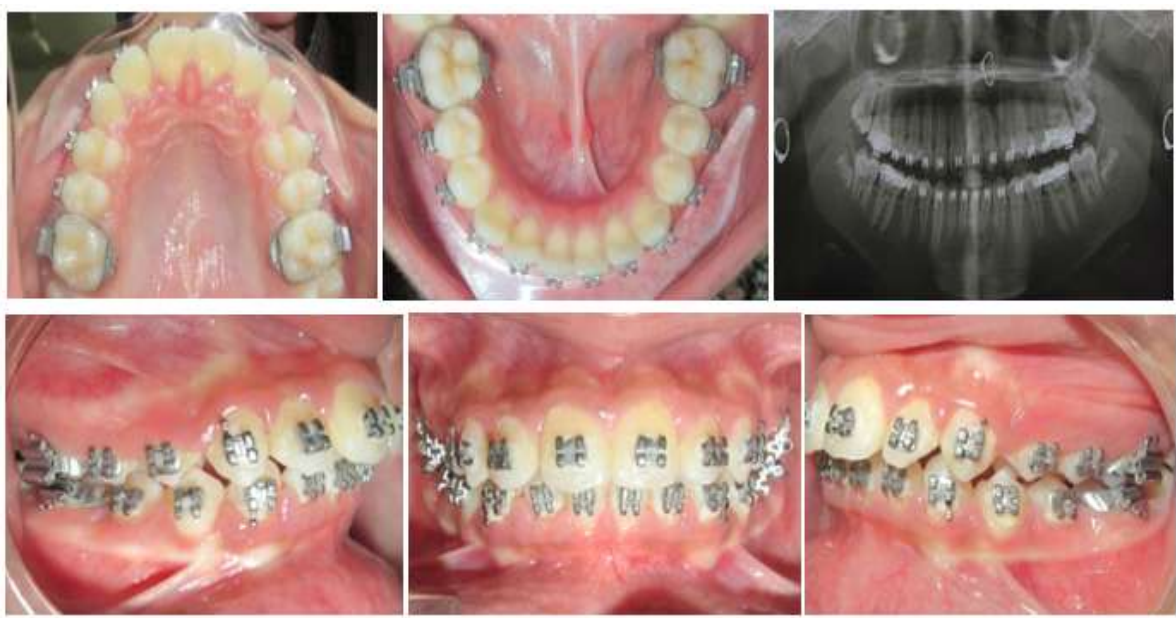

Fig: 4 Current Status Records (Extraoral, Intraoral And Raidographs)

\section{Discussion}

Regarding the therapeutic choices for growing skeletal Class II patients, many studies have reported that functional appliances are highly effective in achieving better relationships between the maxilla and the mandible. Twin-block appliances, among other functional appliances, have proven to be comfortable, esthetic, and efficient. ${ }^{1-3}$ Twin-block appliances have several advantages; they are well-tolerated by patients, easy to repair, and suitable for use in the permanent and mixed dentition. ${ }^{15,16}$

However, there are also some potential disadvantages that include proclination of the mandibular incisors and the development of posterior open bites. ${ }^{17-19}$ Management of distal occlusion with functional appliances can lead to improvement in orofacial function through better muscle adaptation concurrent to the dental and skeletal changes achieved. Ideal timming for orthopaedic treatment for mandibular deficiency is after onset of pubertal growth spurt. ${ }^{20}$ Orthopaedic phase and Orthodontic treatment phase should be combined in one single treatment. Success with this treatment result depends upon slight overcorrection of buccal segments (molars and canine) to a super class I, which builds anchorage into the system prior to placement of the fixed appliances and allows for a slight rebound.

In our patient, the cephalometric analysis indicated mandibular retrusive positioning, reduced lower facial height, deep curve of Spee, flaring maxillary incisors, and severe overjet and overbite. Using the Hybrid Functional Appliance, we achieved a favorable skeletal, dental, and soft tissue relationships were obtained. The severe deep overjet was corrected. Class I canine and molar relationships on both sides were also achieved. The profile was greatly improved. The cephalometric analysis indicated a significant skeletal anteroposterior reduction. The ANB angle decreased by $3^{0}$, and the Wits value decreased by $2.5 \mathrm{~mm}$. The positions of the maxillary incisors were significantly affected (U1-SN decreased from $115^{\circ}$ to $106^{\circ}$ ), whereas the mandibular incisors were not significantly proclined by the treatment (L1-MP slightly increased by $3^{0}$ ). The active treatment phase produced an overjet correction of $9 \mathrm{~mm}$ (from $12 \mathrm{~mm}$ to $3 \mathrm{~mm}$ ) and the increase of nasolabial and labiomental angle with presence of competent lips.

Table 1 Cephalometric Analysis:

\begin{tabular}{|c|c|c|c|c|}
\hline Variable & Normal & $\begin{array}{c}\text { Pre } \\
\text { Treatment }\end{array}$ & $\begin{array}{c}\text { Post } \\
\text { Functional }\end{array}$ & $\begin{array}{c}\text { Current } \\
\text { Treatment }\end{array}$ \\
\hline \multicolumn{5}{|c|}{ Sagittal Skeletal Relationship } \\
\hline SNA & $82^{\circ}$ & $74^{\circ}$ & $76^{\circ}$ & $76^{\circ}$ \\
\hline SNB & $80^{\circ}$ & $68^{\circ}$ & $73^{\circ}$ & $73^{\circ}$ \\
\hline ANB & $2^{\circ}$ & $6^{\circ}$ & $3^{\circ}$ & $3^{\circ}$ \\
\hline Wits Appraisal & $\begin{array}{c}\mathrm{F} 0 \mathrm{Mm}, \\
\mathrm{M}+1 \mathrm{~mm}\end{array}$ & $3 \mathrm{~mm}$ & $0.5 \mathrm{~mm}$ \\
\hline $\begin{array}{c}\text { Mcnamara Eff. } \\
\text { Maxillary Lenth }\end{array}$ & $95.2 \pm 3.2 \mathrm{Mm}$ & $79 \mathrm{~mm}$ & $87 \mathrm{~mm}$ & $87 \mathrm{~mm}$ \\
\hline $\begin{array}{c}\text { Mcnamara Eff. } \\
\text { Mandibular Lenth }\end{array}$ & $\begin{array}{c}120.6 \pm 3.2 \\
\mathrm{Mm}\end{array}$ & $99 \mathrm{~mm}$ & $112 \mathrm{~mm}$ & $112 \mathrm{~mm}$ \\
\hline \multicolumn{7}{|c|}{ Dental To Skeletal Relationship } & & $6 \mathrm{~mm} / 26^{\circ}$ \\
\hline $\begin{array}{c}\text { Upper Incisor to NA } \\
\text { (mm/deg) }\end{array}$ & $4 \mathrm{Mm} / 22^{\circ}$ & $12 \mathrm{~mm} / 34^{\circ}$ & $8 \mathrm{~mm} / 28^{\circ}$ & $6 \mathrm{~mm} / 29^{\circ}$ \\
\hline $\begin{array}{c}\text { Lower Incisor to NB } \\
\text { (mm/deg) }\end{array}$ & $4 \mathrm{Mm} / 25^{\circ}$ & $5 \mathrm{~mm} / 26^{\circ}$ & $8 \mathrm{~mm} / 30^{\circ}$ & $106^{\circ}$ \\
\hline Upper Incisor to SN Plane & $102^{\circ}$ & $115^{\circ}$ & $110^{\circ}$ & \\
\hline
\end{tabular}




\begin{tabular}{|c|c|c|c|c|}
\hline $\begin{array}{c}\text { Lower Incisor to Mandibular } \\
\text { Plane Angle (IMPA) }\end{array}$ & $90^{\circ} \pm 3^{\circ}$ & $97^{\circ}$ & $102^{\circ}$ & $100^{\circ}$ \\
\hline Inter- Incisal Angle & $135^{\circ}$ & $108^{\circ}$ & $116^{\circ}$ & $119^{\circ}$ \\
\hline Lower Incisor to AP Line & $1-2 \mathrm{Mm}$ & $1 \mathrm{~mm}$ & $3.5 \mathrm{~mm}$ & $3.5 \mathrm{~mm}$ \\
\hline \multicolumn{5}{|c|}{ Soft Tissue Relationship } \\
\hline Upper Lip to Ricketts E Plane & -2 To $-3 \mathrm{Mm}$ & $1.5 \mathrm{~mm}$ & $-1 \mathrm{~mm}$ & $-1 \mathrm{~mm}$ \\
\hline $\begin{array}{c}\text { Lower Lip to Ricketts E } \\
\text { Plane }\end{array}$ & -1 To $-2 \mathrm{Mm}$ & $1 \mathrm{~mm}$ & $0 \mathrm{~mm}$ & $-0.5 \mathrm{~mm}$ \\
\hline Nasolabial Angle & $102^{\circ} \pm 8^{\circ}$ & $90^{\circ}$ & $94^{\circ}$ & $96^{\circ}$ \\
\hline Labiomental Angle & $120^{\circ} \pm 9^{\circ}$ & $104^{\circ}$ & $124^{\circ}$ & $120^{\circ}$ \\
\hline
\end{tabular}

\section{Conclusion}

Comparing the two groups of subjects at the peak of pubertal growth treated with the functional appliance by stepwise advancement produced greater skeletal effects than did single-step protrusion in terms of mandibular advancement and augmentation in mandibular length, with similar dental changes. The advantages of double advancement treatment approach have been made evident and in the opinion of the authors are useful tools in the armentarium of the clinician.

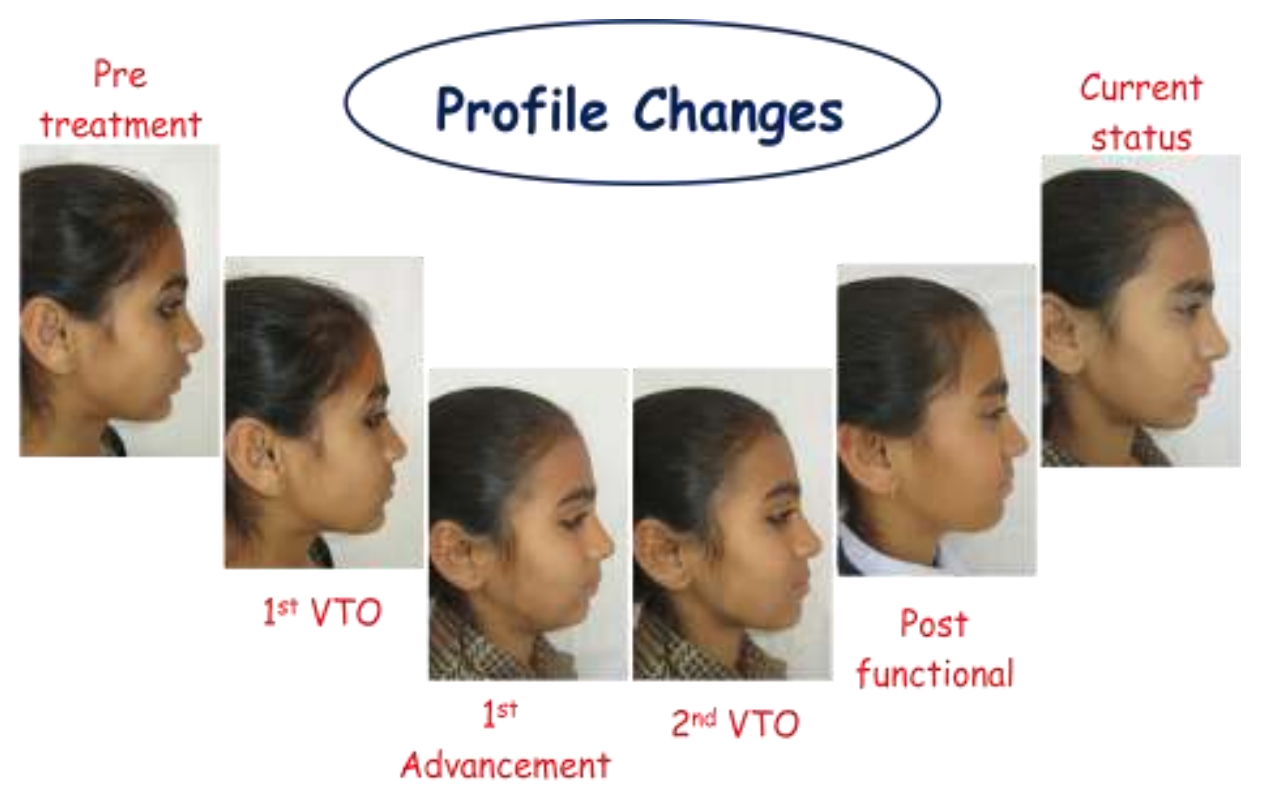

\section{References}

[1]. McNamara JA. Components of Class II malocclusion in children 8-10 years of age. Angle Orthod 1981;51:177-202.

[2]. Clark WJ. The twin block traction technique. Eur J Orthod 1982;4:129-38

[3]. Clark W. Design and management of twin blocks: reflections after 30 years of clinical use. J Orthod 2010;37:209-16.

[4]. Hagg U, Pancherz H. Dentofacial orthopaedics in relation to chronological age, growth period and skeletal development. An analysis of 72 male patients with Class II Division 1 malocclusion treated with Herbst appliance. Eur J Orthod. 1988;10:169-176.

[5]. Cozza P, Baccetti T, Franchi L, De Toffol L, McNamara JA Jr. Mandibular changes produced by functional appliances in Class II malocclusion: a systematic review. Am J Orthod Dentofacial Orthop. 2006;129:599.e1-e12.

[6]. Yang X, Zhu Y, Long H, et al. The effectiveness of the Herbst appliance for patients with Class II malocclusion: a metaanalysis. Eur J Orthod. 2015.doi:10.1093/ejo/cjv057

[7]. Ruf S, Pancherz H. Dentoskeletal effects and facial profile changes in young adults treated with the Herbst appliance. Angle Orthod. 1999;69:239-246.

[8]. Kinzinger G, Diedrich P. Skeletal effects in class II treatment with the functional mandibular advancer (FMA) J Orofac Orthop. 2005;66:469-490.

[9]. Ruf S, Pancherz H. Herbst/multibracket appliance treatment of Class II Division 1 malocclusions in early and late adulthood. A prospective cephalometric study of consecutively treated subjects. Eur J Orthod. 2006;28:352-360.

[10]. Pancherz H, Malmgren O, Hagg U, Omblus J, Hansen K. Class II correction in Herbst and Bass therapy. Eur J Orthod. 1989;11:1730.

[11]. Hagg U, Rabie AB, Bendeus M, Wong RW, Wey MC, Du X et al. Condylar growth and mandibular positioning with stepwise vs maximum advancement. Am J Orthod Dentofacial Orthop. 2008;134:525-536. 
[12]. Rabie AB, Chayanupatkul A, Hagg U. Stepwise advancement using fixed functional appliances: experimental perspectives. Semin Orthod. 2003;9:41-46.

[13]. Graber TM. Functional appliances. In: Graber TM, Vanarsdall RL, Vig KWL, eds. Orthodontics, Current Principles and Techniques. St. Louis: Elsevier Mosby; 2005.

[14]. Isil Aras; Aylin Pasaoglu; Sultan Olmez; Idil Unal; Ali Vehbi Tuncer; Aynur Aras. Comparison of stepwise vs single-step advancement with the Functional Mandibular Advancer in Class II Division 1 treatment. Angle Orthod 2016. DOI: $10.2319 / 032416-241.1$

[15]. Trenouth MJ. Proportional changes in cephalometric distances during Twin Block appliance therapy. Eur J Orthod 2002;24:485-91.

[16]. Patel HP, Moseley HC, Noar JH. Cephalometric determinants of successful functional appliance therapy. Angle Orthod 2002;72:410-7.

[17]. Mills CM, McCulloch KJ. Posttreatment changes after successful correction of Class II malocclusions with the Twin-block appliance. Am J Orthod Dentofacial Orthop 2000;118:24-33.

[18]. Saikoski LZ, Canc,ado RH, Valarelli FP, de Freitas KM. Dentoskeletal effects of Class II malocclusion treatment with the Twin Block appliance in a Brazilian sample: a prospective study. Dent Press J Orthod 2014;19:36-45.

[19]. Peilun Li, Jing Feng, Gang Shen, and Ning Zhao. Severe Class II Division 1 malocclusion in an adolescent patient, treated with a novel sagittal-guidance Twin-block appliance. Am J Orthod Dentofacial Orthop 2016;150:153-66.

[20]. McNamara, et al. treatment timming for twin-block therapy. Am J Orthod Dentofacial Orthop 2000;118:159-70. 